\title{
Sentidos y procesos de la Justicia en Equidad en Armenia, Quindío*
}

\author{
Senses and Processes of Justice in Equity in Armenia, Quindio \\ Sentidos e processos da Justiça em Equidade em Armênia, Quindio
}

Jose Luis Rivera García ${ }^{* *}$

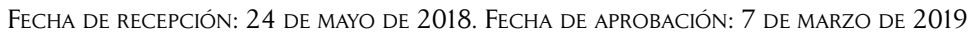

Doi: http://dx.doi.org/10.12804/revistas.urosario.edu.co/sociojuridicos/a.6834

Para citar: Rivera García, J. L. (2019). Sentidos y procesos de la Justicia en Equidad en Armenia, Quindío. Estudios Socio-Jurídicos, 21(2), 197-226. Doi: http://dx.doi.org/10.12804/revistas.urosario.edu.co/sociojuridicos/a.6834

\section{RESUMEN}

Pese a que han pasado más de diez años de implementación de la Justicia en Equidad en la capital del Quindío, con la primera elección de jueces de paz (El Tiempo, 2002) y el primer nombramiento de conciliadores en equidad (Tribunal Superior de Armenia, 2006), hasta hoy poco se sabe de su desarrollo en la ciudad, pues no hay registro histórico oficial o académico que permita dar cuenta de información sistematizada al respecto, en especial sobre qué significados subyacen a sus procesos y cómo aquellos determinan o influyen en ellos. Este artículo responde a la investigación que aportó a esas preguntas, al describir las nociones y significados de operadores y usuarios sobre la justicia en equidad en la ciudad de Armenia, Quindío, generando conocimiento riguroso y contextuado sobre el tema (contando con perspectivas y expresiones propias de los protagonistas) y proponiendo elementos de debate para su comprensión en Colombia, afirmando que el sentido de lo justo comunitario tiene en los juegos de persuasión, aquellos en que entran diversos actores (con sus discursos) durante los diálogos de las audiencias, un momento importante de su continua configuración y reelaboración social.

Palabras clave: pluralidad jurídica, sentido de lo justo comunitario, conflictos cotidianos, retórica.

* Este artículo es resultado del proyecto de investigación "Nociones y significados sobre la justicia en equidad de los operadores y usuarios en Armenia, Quindío" (2017), realizado como modalidad de trabajo de grado para optar por el título de Trabajador Social en la Universidad del Quindío, Armenia, Colombia.

** Trabajador social, Facultad de Ciencias Humanas y Bellas Artes de la Universidad del Quindío. Correo electrónico: jlriverag@uqvirtual.edu.co. ORCID: //orcid.org/0000-0003-3848$340 X$. 


\section{ABSTRACT}

Despite the more than ten years of the Justice in Equity implementation in the capital of Quindio, with the first election of peace judges (El Tiempo, 2002) and the first conciliators in equity appointed (Tribunal Superior de Armenia, 2006), little is known of its development in the city. There are no official or academic records that evidence systematized information about it, especially about what meanings underlie its processes and how those determine or influence the latter. This article responds to the research contribution to these questions by describing the notions and meanings of the operators and users of Justice in Equity in the city of Armenia, Quindio, generating rigorous and contextualized knowledge (with perspectives and expressions of the protagonists). The investigation proposes debate elements for the understanding of it in Colombia; states that the communitarian sense of just in the persuasion games of diverse actors' during the audiences' dialogues, which are an essential moment of their social configuration and continuous social reworking.

Keywords: Legal pluralism, community sense of justice, every day conflicts, rhetoric.

\section{RESUMO}

Embora já passaram mais de 10 anos de implementação da Justiça em Equidade na capital do Quindío, com a primeira eleição de juízes de paz (El Tiempo, 2002, 29 de setembro) e a primeira nomeação de conciliadores em equidade (Tribunal Superior de Armênia, 2006), até hoje, pouco é sabido de seu desenvolvimento na cidade, pois não há registro histórico oficial ou acadêmico que permita dar conta de informação sistematizada ao respeito, especialmente sobre quais significados subjazem a seus processos e como aqueles determinam ou influem nos últimos. Este artigo responde à investigação que aportou a essas perguntas ao descrever as noções e significados de operadores e usuários sobre a Justiça em Equidade na cidade de Armênia, Quindío, gerando conhecimento rigoroso e contextuado (contando com perspectivas e expressões próprias dos protagonistas) sobre o tema e propondo elementos de debate para a compreensão do mesmo na Colômbia, afirmando que o sentido do justo comunitário tem nos jogos de persuasão, aqueles em que entram diversos atores (com seus discursos) durante os diálogos das audiências, em um momento importante de sua continua configuração e reelaboração social.

Palavras-chave: pluralidade jurídica, sentido do justo comunitário, conflitos cotidianos, retórica. 


\section{Introducción}

El auge de ciertas formas de justicia comunitaria se debe a la denominada 'litigiosidad represada' (Uprimny, 1999), esto es, un buen número de conflictos cotidianos que no acceden a administración de justicia - situación a la que aporta de manera importante la congestión de los despachos judiciales- y que al quedarse sin institución legítima que los tramite, desencadenan (o agravan) las violencias en Colombia, a través de prácticas de justicia privada. Así, la respuesta institucional genera instancias informales y la Justicia en Equidad aparece como alternativa frente a la frecuente inoperancia de la justicia ordinaria y a las vías violentas para resolver conflictos.

El Quindío no es ajeno a las dinámicas de violencia cotidiana, como lo demuestran las altas cifras de homicidios en años recientes, publicadas por el Observatorio Social de la Universidad del Quindío (Fernández, Vega \& Giraldo, 2013). Según el Observatorio, se eleva como hipótesis importante la que explica que estas dinámicas violentas devienen de conflictos urbanos asociados con disputas territoriales de asentamientos y vecindarios, competencia por servicios públicos, delincuencia convencional y violencia doméstica. Por ello, se hace necesario indagar y visibilizar alternativas de canalización de dichos conflictos, cuyas características permitan la participación directa y determinante de sus actores para aportar a la coexistencia pacífica.

A pesar de ser amplio el panorama de la Justicia en Equidad en Colombia, al alcanzar cerca de 10000 operadores y alrededor de 120000 conflictos tramitados anualmente (Ministerio de Justicia, 2016; CEJ, 2011) no es extenso el conocimiento contextuado sobre esta forma de justicia, pues no hay publicado un seguimiento periódico oficial a la Justicia en Equidad para dar cuenta de su funcionalidad, y las investigaciones empíricas (que no abundan) han abordado sobre todo, desde la perspectiva del derecho, la dimensión cuantitativa, como las realizadas en Barranquilla (Illera, García \& Ramírez, 2012; Ramírez, Illera \& Llinás, 2012) y Bogotá (Pinzón, 2007), dejando de lado qué significados de justicia subyacen a sus procesos y cómo estos influyen en los últimos, aspectos de interés de la perspectiva socio-jurídica. 
Junto con otros trabajos en el país (Atehortúa \& Hincapié, 2005; Torregrosa, 2011; Torregrosa \& Torregrosa, 2014, y Ardila \& Castro-Herrera, 2016) este busca aportar en el tema, al dar respuestas a aquellos interrogantes, en particular, partiendo de las expresiones singulares de los sujetos que la configuran, esto es, operadores y usuarios en contextos particulares de las comunas 1, 5 y 6 de la ciudad de Armenia (Quindío) durante 2017, describiendo sus nociones y significados alrededor del sentido de lo justo comunitario, el conflicto y el vínculo entre la Justicia en Equidad y la cohesión social.

Para ello, primero se presentan los planteamientos teórico-conceptuales que soportaron la investigación, como proposiciones explicativas, definiciones y supuestos de trabajo. Luego, se expone la metodología utilizada, puntualizando el enfoque y el diseño metodológico, para dar paso a la descripción de los resultados de acuerdo con las categorías prestablecidas y las emergentes. Por último, se plantean las conclusiones e implicaciones de la Justicia en Equidad como tema de investigación para los trabajadores sociales.

\section{Pluralidad de ordenamientos jurídicos, justicia comunitaria y Justicia en Equidad}

Al hablar de Justicia en Equidad hay que explicar el concepto de justicia comunitaria, por lo que se parte de la premisa que aporta De Sousa Santos (2001), que afirma que las sociedades contemporáneas son constelaciones jurídicas, esto es, que ellas no están regidas por un solo ordenamiento jurídico, sino por una pluralidad de los mismos. Lo anterior implica que el pretendido monopolio de justicia por parte del Estado ya no procede - de hecho, para el autor, nunca hubo tal-y más bien la justicia oficial está en constante relación y disputa con otros ordenamientos jurídicos con particularidades espacio/temporales, culturales y sociales, y diferencias claras en sus propios procesos y formas de tramitar ciertos conflictos.

En un plano analítico, lo que hace equiparables a las diversas formas de administración de justicia que coexisten en constelaciones jurídicas son, para Santos (2001), los elementos presentes en todo ordenamiento 
jurídico como formas de comunicación y estrategias de decisión, a saber: retórica, burocracia y violencia.

la retórica (...) [se basa] en la persuasión o el convencimiento a través de la movilización del potencial argumentativo de secuencias y artefactos verbales y no verbales comúnmente aceptados. La burocracia (...) [se basa] en imposiciones autoritarias por medio de la movilización del potencial demostrativo de procedimientos regularizados, patrones normativos. Por último, la violencia (...) fundada en la amenaza a partir de la fuerza física. (p. 134)

La diferencia radica en las formas de articulación de estos tres elemen$\operatorname{tos}^{1} \mathrm{y}$ las cargas (el carácter dominante o recesivo) que tengan dentro del ordenamiento jurídico. Santos (2001) llega a la conclusión de que hay una relación marginal entre estos, es decir, la presencia predominante de uno va en detrimento de la presencia del otro. Violencia y burocracia han crecido a la par, así que su predominio suele implicar la ausencia o subordinación de la retórica. Propone el mismo autor, sobre el derecho estatal, que "la retórica está hoy no solo cuantitativamente reducida, sino 'contaminada' e 'infiltrada' por la burocracia y la violencia como componentes estructurales dominantes" (Santos, 2001, p. 136). Este es un supuesto de trabajo que se retoma en el análisis.

Para Santos (2001) el derecho estatal no es ajeno a la pluralidad jurídica, de hecho, específicamente en Colombia, compite fuertemente con ordenamientos paralelos en la complejidad que representa su territorio y se ha visto afectado por una hibridación jurídica, tanto a nivel estructural como a nivel de las representaciones jurídicas y la vida cotidiana, en la que ha terminado combinándose (a veces como complemento, otras veces como competencia y con mayor frecuencia, dadas las múltiples diferencias en cuanto a normatividad y racionalidad, como confrontaciones) con otros derechos.

Para comprender lo anterior se retoman aquí dos de las dimensiones que plantea Santos (2001) al examinar la pluralidad jurídica: oficial/

Son tres los tipos de articulación: la covariación, la combinación socio-política y la interpenetración estructural, las cuales se explican en detalle en Santos, Boaventura de Sousa (2001). El caleidoscopio de las justicias en Colombia. Bogotá: Siglo del Hombre Editores (2001). 
no oficial y formal/informal. La dimensión oficial/ no oficial "permite identificar por un lado el derecho estatal, y por el otro una multitud de derechos y justicias locales, urbanos y campesinos: justicia indígena, justicia guerrillera, justicia de bandas, justicia miliciana y justicia paramilitar." (Santos, p. 146, 2001). Mientras tanto, con la dimensión formal/ informal diferencia a las justicias que imperan en el centro del sistema (formal) de las que sobresalen en la periferia del mismo (informales). Se define la justicia informal como "una forma de derecho y de justicia dominada por la retórica y en la cual, tanto violencia como burocracia están presentes de manera marginal" (Santos, 2001, p. 147).

Así, la justicia comunitaria, dentro la pluralidad jurídica, se puede definir como justicia informal, en ocasiones oficial. ${ }^{2}$ Éste último carácter se define de acuerdo a si es reconocida por el Estado o no, y en todo caso se referirá a un ordenamiento jurídico cívico y no impuesto por grupos armados, salvo cuando tal diferencia no se establece claramente, como sucede en el caso del campo jurídico de la Sierra de la Macarena, expuesto por Nicolás Espinosa (2009). ${ }^{3}$

Según lo planteado, como justicia comunitaria oficial/informal se denomina la Justicia en Equidad. A decir de Ardila (2006) esta es la impulsada desde el Estado, en su propio proceso de informalización de la justicia, con normatividad que la sustenta y define sus competencias, así como con sus procedimientos específicos (es el caso de los jueces de paz y de los Mecanismos Alternativos de Solución de Conflictos (MASC) en diferentes países). El mismo autor plantea que el principio orientador de este tipo de justicia comunitaria se remonta históricamente al lus Aequum del derecho romano y la equity de derecho anglosajón, como alternativa al principio de seguridad jurídica o sujeción estricta a la ley para "realizar justicia".

Así, Ardila (2006) plantea que la Justicia en Equidad tiene el potencial de ser más oportuna y legítima, pues el operador "está obligado a acercarse

2 Esta definición es funcional al análisis de la Justicia en Equidad, sin embargo, estas dimensiones o dicotomías, como bien lo ha señalado Ardila (2016) en su tesis doctoral, no agotan la definición de la justicia comunitaria, pues implica también (y sustancialmente) características culturales como la identidad y el sentido de pertenencia.

3 Una configuración singular de articulación entre la justicia guerrillera y la justicia comunitaria (campesina). Ver: Espinosa, N. (2009). “El campo jurídico del 'otro derecho' en la Sierra de La Macarena. Elementos para un análisis crítico de la justicia alternativa en una zona de fuerte conflicto armado". Revista Colombiana de Sociología 32(2). 
al sentir colectivo de justicia que existe en el ámbito social en el cual ejerce su labor" (p. 85), es decir, que las decisiones tomadas son contextualizadas y su función reguladora ya no proviene del Estado únicamente, pues este no ha asumido (ni asumirá) toda la carga de la conflictividad social, sino de la 'comunidad' que aparece con un nuevo auge (Ardila, 2004) al vincular valores y costumbres para guiar los comportamientos sociales.

Uprimny (1999) realiza una distinción en tipos ideales entre las formas de administrar justicia, de acuerdo con sus principios orientadores.

En un caso gracias a la pura discusión argumental, las partes y un tercero mediador llegan a una solución a la cual todos adhieren consensualmente: es un modelo de justicia conciliadora, en la cual hay un predominio de la retórica, en virtud de la cual el derecho casi se confunde con técnicas de negociación y de conciliación (autocomposición del litigio). En el otro caso de figura, la solución a las partes es impuesta por la fuerza, luego de ser decidida por el aparato burocrático, quien determina los criterios técnico-jurídicos, quién es el vencedor y quién es el vencido en la controversia. Es el modelo adjudicativo, en el cual hay un predominio de la heterocomposición y de la amenaza de violencia y la actividad burocrática sobre la argumentación teórica. (p. 78)

La Justicia en Equidad puede asemejarse como tipo ideal a un modelo de justicia conciliadora, en el que la retórica (posible a través del lenguaje y que se torna como discusión) domina sobre la violencia y la burocracia, aunque las últimas no desaparecen, sino que tienen un carácter recesivo, al validar legalmente (ante el sistema jurídico oficial) la operatividad y los acuerdos de las figuras de Justicia en Equidad. En esta definición coinciden Uprimny (1999), Santos (2001) y Ardila (2006), por lo que es usual que la llamen instancia "mixta" o "bisagra" entre el sistema judicial formal y las formas y sentidos de lo justo socialmente configurados.

\section{Metodología}

Como figura de justicia orientada por estructuras normativas extralegales, la investigación se dedicó a la realidad subjetiva que la contiene y 
tuvo un enfoque cualitativo al prestar especial atención a las perspectivas de los sujetos y a los momentos de las audiencias de Justicia en Equidad, para "reconstruir la realidad tal y como la observan los actores" (Hernández Sampieri, Fernández Collado \& Batista Lucio, 2010, p. 10). Así, el estudio no pretendió la demostración de hipótesis ni la generación de teorías sustantivas, sino la contrastación entre referentes teóricos y experiencia vívida, examen tras el cual surgieron nuevos elementos que aportaron a dar cuenta del objeto de investigación como fenómeno global, partiendo de un escenario particular, ${ }^{4}$ donde cobraba suma importancia el contexto y tiempo, dónde y cuándo se desarrolló, así como los puntos de vista, valores y creencias de los informantes en forma de narraciones. ${ }^{5}$

Para la selección de los informantes se combinaron tres formas de muestreo clasificadas por Hernández Sampieri, et al., (2010), a saber: la muestra en cadena, la muestra variada y la muestra por participación voluntaria. Se estableció un total de cuatro (4) operadores en equidad entrevistados, dos en la comuna 1, una conciliadora en equidad y un juez de paz (Casa de Justicia Cañas Gordas), un juez de paz de la comuna 6 y una jueza de paz de la comuna 5 . En cuanto a los usuarios se estableció un total de cuatro (4) usuarios entrevistados (dos mujeres y dos hombres) correspondientes al sitio de referencia de cada operador y cuya audiencia de conciliación fue observada por el investigador. Se obtuvo entonces una muestra total de ocho (8) informantes.

Se emplearon como instrumentos investigativos la observación y la entrevista semi-estructurada, pues a través de la descripción detallada de las audiencias, los encuentros informales y las preguntas dirigidas intencionalmente sobre las adjetivaciones, discursos y frases usadas por los sujetos para representar la Justicia en Equidad de acuerdo a su experiencia y características socio-culturales, se captaron los sentidos y procesos alrededor de la instancia.

Se acoge acá el termino sentido para sintetizar en él las categorías originales de la investigación: nociones y significados, pues el sentido

4 Para ampliar al respecto véase el diseño emergente constructivista de Virginia Henderson en Hernández Sampieri, N., Fernández Collado, N. \& Batista Lucio, N. (2010). Metodología de la investigación. Ciudad de México: McGraw-Hill.

5 Estas fueron definidas por Charmaz como "expresiones vivas". (2000, citado en Hernández Sampieri, et al., 2010, p. 497). 
puede entenderse como la orientación de los significados del lenguaje, producidos (y reelaborados) en las relaciones intersubjetivas y en contextos culturales particulares (Gergen, 2006), dentro de los cuales, a su vez, aparecen las nociones como formas elementales (expresiones) de atribución de sentido (Atehortúa \& Hincapié, 2005) a la acción humana.

En el término proceso se resume, además de los actos perlocucionarios que se develan en las audiencias (Searle, 2001, en Cardenas Mejía, 2006), sus momentos y su funcionamiento, detallados en el recorrido hecho por las categorías y subcategorías.

Entonces, la presentación de los resultados se hizo por medio de narraciones y la estrategia para el análisis de las narraciones como datos fue la codificación abierta por unidades de sentido, de la que surgieron categorías iniciales de significado a través de un método de comparación continua. "Las categorías se basan en los datos recolectados (entrevistas, observaciones, anotaciones y demás datos). Las categorías tienen propiedades representadas por subcategorías, las cuales son codificadas (las subcategorías proveen detalles de cada categoría)" (Hernández Sampieri, et al., 2010, p. 494).

Tres fueron las categorías iniciales: la primera fue el sentido de lo justo comunitario, y sus subcategorías fueron significado de justicia, normas sociales y legitimidad; la segunda, conflicto, y sus subcategorías, noción de conflicto, tipología del conflicto y motivación del conflicto, y la tercera, cohesión social, y sus subcategorías actuar en comunidad e inclusión intercultural.

La subcategoría institucionalidad, correspondiente a la primera categoría inicial, fue un concepto emergente, al igual que la categoría retórica y sus subcategorías emotividad, tradición y coacción.

\section{Resultados}

\section{Sentido de lo justo comunitario}

Es una categoría elaborada a partir de los planteamientos de Ardila $(2006)^{6}$ para caracterizar la Justicia en Equidad, en la que lo justo se

6 El autor se refiere originalmente al sentido colectivo de justicia o justo comunitario, equiparándolos y sin hacer distinción alguna. En este artículo se presenta, en las conclusiones, una propuesta de definición de la categoría a la luz de los resultados. 
constituye a partir de estructuras normativas extralegales, reconocidas socialmente y que permiten tomar decisiones y llegar a acuerdos. Para hacerse efectivo, el sentido de lo justo comunitario comprende la existencia de normas sociales y su reconocimiento, esto es, el que de ellas se desprendan significados de justicia y tener cierta legitimidad en el contexto social en el que se instituyen.

El significado de justicia identificado entre operadores y usuarios de la Justicia en Equidad fue congruente con el concepto originado en el paradigma distributivo de justicia. Los operadores lo comprenden como dar a cada cual lo que le corresponde, esto es, compensar o retribuir beneficios, cargas, comportamientos o recursos (Marion Young, 2000; Ardila, 2006), y dentro de las conciliaciones, está ligado a la noción de equidad como equiparar las situaciones que los usuarios presentan y otorgar oportunidades (convenidas) para resarcir daños, perjuicios, deudas, atrasos, molestias e inconformidades en condiciones de igualdad.

Yo entiendo por justicia [...] dentro de la conciliación es como colaborarle a que la parte afectada reciba lo que ha perdido, ¿si me entiende?, pues porque a veces la gente la justicia se la toma por su propia mano [...]. (Operador 1: O1, comunicación personal, 26 de mayo de 2017)

Las normas sociales son asumidas por los operadores como elementos persuasivos, dado que permiten regular las emociones y actitudes airadas durante las audiencias. Para los usuarios son comparables con las "normas de convivencia" y la "educación", sobre todo la que es resultado de la crianza. Para los informantes, el acatamiento de normas sociales facilita las relaciones sociales pacíficas y fomenta el "ánimo conciliatorio" cuando se presentan conflictos. Dentro de las audiencias las normas sociales se evocan como deberes que aducen valores, con un contenido prescriptivo que busca conducir moralmente los comportamientos.

La mayoría de las cosas es la educación de la persona [...]. Si un niño se crió con violencia él [...] va ir a de una vez a atacar a la persona con las malas palabras. Pero una persona culta [...] llama a la persona y le dice "Don Fulano, tenemos que hablar, que esto y lo otro", y entonces ya se ponen los pro y los contra para llegar a una conciliación. (Usuario 2: U2, comunicación personal, 27 de julio de 2017) 
En el conflicto vecinal, $\mathrm{O} 1$ instó a las usuarias a que indicaran a sus hijos que no intervinieran en el conflicto que ellas sostenían a través de resaltar su "deber como madres" de ordenar o corregir comportamientos de sus hijos cuando fueran en contravía del respeto y estimularan el odio, a lo que ambas usuarias asentían con la cabeza. (Audiencias con O1, observación directa, 22 de junio de 2017).

Una narración peculiar de un operador dice: "Pero la normatividad en Colombia es demasiado amplia y eso genera antes confusión y que la gente vulnere la justicia y los derechos de todos (...)" (Operador 3: O3, comunicación personal, 27 de mayo de 2017). Ésta permite retomar el planteamiento de Chinchilla (2008) sobre la anomia por exceso de normas y no por su ausencia. Dicho exceso constituye paradójicamente un vacío, pues estas no parecen alcanzar cercanía con la 'conciencia colectiva' y son distinguidas más por su utilidad instrumental y su potencial impositivo, antes que por su valor ético y significado social (Chinchilla, 2008). Las leyes, en suma, no alcanzan a ser vislumbradas por las personas del común y parecen sólo de dominio de expertos.

Ante la ineficacia y el débil vínculo de las leyes con elementos de cohesión social como las tradiciones, valores identitarios y normas sociales (aunque diversos en las sociedades contemporáneas), la seguridad jurídica como criterio para realizar lo justo pierde pertinencia social y la equidad aparece como posibilidad alterna y legítima, al acogerse al sentido de lo justo comunitario, más cercano a la cotidianidad, comprensión y acatamiento de los personas de a pie y al ser válida para la justicia oficial/ formal, evitando la expresión criminal de la anomia.

La forma como los informantes consideran que se resuelven los conflictos confiere legitimidad a la instancia, esto es, reconocida como la institución adecuada para ejercer el poder de administrar de justicia. El diálogo mediado como alternativa pacífica de tramitar los conflictos sobresale en la Justicia en Equidad. A ese diálogo lo caracteriza el trato "respetuoso" o "cordial" entre los participantes, el uso moderado por el operador de la palabra y que los artefactos verbales utilizados estén desprovistos de lenguaje técnico del derecho positivo, acercándose a la manera como los sujetos involucrados se expresan comúnmente. 
Uno trata de que las dos personas involucradas en el conflicto nos vean igualitos a ellos, que tenemos los mismos problemas, no tenemos subido el ego de ser profesional o de que nos digan jueces, o que nos veamos montados en un palacio y hablemos tecnicismos que de pronto las otras personas ni entienden, sino que ese diálogo directo rebaja y disminuye el sentido de prevención que tengan los demás y la alternativa de poder dialogar y como de desahogarse sin necesidad de recurrir a una violencia [...]. (O3, comunicación personal, 27 de mayo de 2017)

En las audiencias de Justicia en Equidad prevalece un sentido consensuado de justicia frente al sentido personal, lo cual es identificable en los relatos de los usuarios. El operador aboga por generar empatía, recapitulando las motivaciones y versiones de cada usuario sobre el conflicto para que éstos sientan lo vivido por el otro como situación propia, aceptando en cierta medida las pretensiones contrarias como razonables, aunque esto no siempre es posible. Entonces se trata de que el acuerdo responda de manera suficiente a los intereses de cada usuario para que se muestren satisfechos, e incluso se recarga la decisión sobre el operador que la plantea como propuesta sujeta a ser aprobada por los envueltos en conflicto. Así, un diálogo impositivo, aunque en apariencia empático, también es posible.

Es una mesa de dialogo [...] cada uno habla sobre el dolor de cada uno, cada uno se defiende y defiende sus propias posiciones y el papel que cada uno representa en ese momento es como una voz, si nadie lo escuchó, aquí se le escucha, cada uno tiene su voz, y tiene su opinión [...] todo el mundo tiene derecho a hablar [...]. (Usuario 1: U1, comunicación personal, 22 de junio de 2017)

El dialogo pues [...] que a ellos les ordenan que tienen que desocupar en el tiempo limitado como uno les dio la fecha. Ehh, porque yo sé que el juez le da un término, le da tres días [...] pero yo les doy 8 o 15 días cuando me faltan y no me quieren desocupar [...] así me haya mentado la madre. (Usuario 3: U3, comunicación personal, 1 de agosto de 2017)

No obstante, la legitimidad parece limitada al tratar de observar a la Justicia en Equidad como institución en Armenia (Quindío). En relación al campo jurídico oficial y a los habitantes del municipio, en general, su legitimidad podría estar reduciéndose a una cuestión privada, al exponerse 
a la subvaloración institucional y a la carencia de un reconocimiento social significativo, sumado a que las iniciativas de asociatividad entre los jueces de paz no han prosperado. Todo lo anterior aparenta estar reproduciendo lo que algunos investigadores han hallado en otros lugares con respecto al conocimiento y uso de las figuras (Illera, et al., 2012). Sin embargo, haría falta una investigación cuantitativa en Armenia que compruebe esta hipótesis.

Hay jueces que no aceptan como prueba la conciliación de nosotros, ni la del juez de paz, ni la mía, jueces que de pronto están recargados a la otra parte, pero la conciliación de nosotros es legal [...]. (O1, comunicación personal, 26 de mayo de 2017)

Uno de los funcionarios del Consultorio Jurídico y Centro de Conciliación de la Universidad Gran Colombia me aclaró que las conciliaciones que allí se hacían eran en derecho, "respetuosas de la ley", contando con operadores certificados o en formación del programa universitario de Derecho. Agregó, enfatizando con cierta severidad marcada por su tono de voz, señas firmes con las manos y el ceño fruncido, que la conciliación en equidad era "una forma de desmeritar y desestimar el Derecho" y que allí la justicia quedaba sujeta a interpretaciones personales, contaminadas de sentido común, lo cual, para él, desvirtuaba que se tratara de una instancia justa y adecuada de resolución de conflictos. (Notas de campo 1: consultas exploratorias, comunicación personal, 6 de marzo 2015)

Entre las elecciones de 2009 y 2016 evidencié la través de artículos de prensal una reducción tanto del número de jueces de paz electos como de votos, pasando de 25 a 12 y de 2.123 a 545, respectivamente. Además, noté que había retrasos hasta de dos años en cada elección, pues de acuerdo con los periodos estipulados de 5 años (art.13 ley 497/99), una debió realizarse en 2007 y la ultima en 2014. (Notas de campo 5: rastreo del proceso, revisión documental, 15 de febrero de 2017)

Uno no tiene esa información con respecto a las instancias, yo no sé qué diferencia hay entre el PARSE, cuando uno pone una denuncia allá y yo no sé aquí, sé que viene a una conciliación pero para llegar aquí yo no sé a dónde hay que ir, la Fiscalía yo no sé a dónde [...] Entonces de pronto hay también cierta desinformación en ese sentido [...]". (U1, comunicación personal, 22 de junio de 2017) 
En ocasiones se presentan transacciones económicas entre usuarios y operadores, las cuales son problemáticas. Por un lado, porque reflejan que la condición de ejercer como operador en equidad ad honorem parece limitar las posibilidades de la instancia, pues deben contar con sus propios recursos, no siempre suficientes, para llevar a cabo todas las actividades inscritas en su quehacer (visitas, emisión de documentos, solicitudes, etc.).

De todas maneras eso causa mucho traumatismo en uno, tiempo, dinero que se pierde: contestación al juzgado, papelería y todo eso. El cliente no le va a pagar a uno, sino que es el propio pecunio de uno ija ja! pero ahí vamos [...]. (O3, comunicación personal, 27 de mayo de 2017)

Por otro lado, el que se dé el cobro genera una distorsión social sobre la figura y compromete su legitimidad. La distorsión social se explica porque parece encaminar lo justo hacia el sentido personal de justicia y simbolizar un cambio de relación de operador-usuario a defensor-cliente, propio del escenario de la justicia oficial/formal (Santos, 2001). La legitimidad queda comprometida en cuanto a legalidad del quehacer, dado que la transacción es en principio irregular (de acuerdo al art.9 de la Ley 497/99 y el art. 83 en la Ley 23/91) pero no del todo injustificada, al destinarse a gastos operacionales y no a lucro o a salario y al no ser un requisito impuesto a los usuarios para acceder a la administración de Justicia en Equidad (no se estaría violando el artículo 19 de la Ley 497/99 ni el numeral 2 del parágrafo del artículo 84 de la Ley 23/91).

En una ocasión $\mathrm{O} 2$ solicitó dinero a uno de los usuarios justificando que el trámite del conflicto necesitaba de traslados a lugares diferentes de la oficina de la Casa de Justicia, por lo que se necesitaba costear el transporte. La transacción, según la denominación del billete que vi, fue de COP 5000. (Audiencias con Operador 2, O2, observación directa, 13 de junio de 2017)

\section{Conflicto}

En las narraciones, la noción de conflicto entre los informantes se asociaba con el disenso, la contradicción y la controversia persistente en las sociedades como indeseables, al irrumpir el orden social trasgrediendo 
normas y desestabilizando el ideal de armonía en las relaciones sociales, potenciando la violencia. Esto sugiere una definición afín a las teorías consensualistas (Lorenzo Cadarso, 1995), que explican el conflicto como disfuncional y consecuencia del desorden.

Conflicto pues que no están en armonía [...]. Si yo tengo un buen concepto suyo, pero si usted llega con grosería, de una vez me indispone, entonces a veces no saben con quién se van metiendo, vienen a los golpes, a las malas palabras [...]. (U2, comunicación personal, 27 de julio de 2017)

De la expresión cotidiana del conflicto, que es la que se manifiesta ante la Justicia en Equidad y relaciona dimensiones socio-económicas, psicológicas, culturales y políticas representadas en recursos escasos, estatus, valores y poder como elementos en disputa en una "situación en que dos o más individuos con intereses contrapuestos entran en confrontación, oposición o emprenden acciones mutuamente antagonistas" (Alzate, 1998, p. 97), ${ }^{7}$ se examinaron las tipologías y motivaciones del conflicto.

En cuanto a la tipología, los operadores destacaron un conflicto comercial en particular, el derivado del incumplimiento del pago de arrendamientos, como de los más persistentes. Este hecho sugiere que la instancia es considerada adecuada, al menos por los usuarios y algunos de los funcionarios que conocen las figuras, para zanjar controversias afines.

Arrendamiento, conflicto entre vecinos, deudas de todo tipo, eso es generalizado, pero más acentuado está el de arrendamiento, donde la gente vive gratis y no paga arriendo, se va debiendo servicios...ése está muy acentuado [...]. (O1, comunicación personal, 26 de mayo de 2017)

Todos los operadores coincidieron en tipificar el conflicto surgido en los arrendamientos de acuerdo a la clasificación legal como "restitución de inmuebles". Se mostraban de acuerdo con que en el contenido de la solución consagrada en acta se estableciera el desalojo de las viviendas

7 En la definición del autor, aunque no sea referenciado en la cita original, se nota una gran influencia del concepto que aporta Lewis Coser en "Las Funciones del Conflicto Social" (1961) Fondo de Cultura Económica. 
o locales por parte de los arrendatarios, por lo que entraban a orientar la negociación de plazos y montos adeudados entre los usuarios en conflicto.

El Operador 4 invita a los usuarios a tomar asiento, indicándoles en qué pupitre quiere ella que se ubiquen. Pide las citaciones y las cédulas de cada usuario, luego empieza la audiencia anotando en el acta de conocimiento el nombre y el número de identidad de cada uno, dejando claro sobre qué tipo de conflicto se discutirá. "Pago de arrendamiento, servicios públicos y restitución del inmueble". (Audiencia con Operador 4: O4, observación directa, 19 de julio de 2017)

De lo anterior surge la cuestión ¿cómo saber si las decisiones surgidas de la instancia, tanto las que son resultado de conciliaciones como las que lo son de la emisión de fallos, no terminen siendo inicuas para un sector de la población (los desempleados sin vivienda propia), lo que supondría arbitrariedades en la Justicia en Equidad "acentuando y reproduciendo relaciones de dominación y explotación" (Uprimny, 1999, p. 312), en sociedades que muestran profundas desigualdades?

Pues, según lo observado, la estimación, en las soluciones consensuadas, de la situación social que motiva los incumplimientos de arrendamiento, permite que lo acordado pueda no efectuarse cabalmente y a la vez que el conflicto no escale hacia expresiones violentas. Prevalece entonces el interés del desalojo, pero bajo condiciones que los participantes consideran igualitarias.

Es por esto que para los operadores no pasan inadvertidos problemas socio-económicos como el desempleo y la pobreza, desequilibrios emocionales de los individuos y valores sociales relacionados con la "convivencia" y el "sentido de pertenencia" como motivaciones importantes de los conflictos. Los usuarios, además de resaltar aspectos económicos, mencionan aspectos culturales, como las diferencias de hábitos y costumbres, y políticos, en las relaciones entre la sociedad civil y el Estado. Se ejemplifican en situaciones hipotéticas que implican conflictos interpersonales notorios en la vida diaria y recurrentes en la instancia.

El hambre, el desempleo, eso es lo que más motiva el conflicto. La persona que vive a toda hora alterada, porque ahora la mayoría de las personas viven alteradas ¿debido a qué? A la situación tan difícil que 
en ese momento está pasando este país [...] una crisis económica [...] porque conflicto puede ser que yo le hable a usted y que usted me conteste con cuatro piedras en la mano [...]. (O4, comunicación personal, 29 de julio de 2017)

No respetar esas diferencias, yo creo que eso es básico, uno tiene que respetar que el otro tiene otro mundo distinto [...] en el momento en que usted respete a su vecino porque es que al él le gusta echarle todos los días agua a las ventanas y lavar el patio y el antejardín [...] o no le gusta salir o no saluda [...] pues él tendrá sus motivos. (U1, comunicación personal, 22 de junio de 2017)

Aunque los actores de la Justicia en Equidad alcanzan a vislumbrar que las motivaciones de los conflictos guardan relación con problemas sociales (arrendamientos y desempleo, por ejemplo) se reconoce que la administración de justicia media sólo en las manifestaciones interpersonales de estos conflictos comerciales, sin resolver las causas que explican su persistencia, lo cual les pone de presente el preguntarse sobre las cuestiones que atañen a la justicia social.

\section{Cohesión social}

En un sentido amplio se refiere a cómo se vinculan las sociedades y las formas de adhesión entre individuo y sociedad -sentido de pertenencia, confianza horizontal y legitimidad-(Barba Solano, 2011). Las sociedades contemporáneas son plurales y diversas, por lo que también lo son los marcos de referencia normativos y valorativos de solidaridad social. La forma de solidaridad social desde la cual se examinó la Justicia en Equidad fue actuar en comunidad (Weber, 1973 [1913]), como la acción racional en que, en una situación particular ante terceros, se reconocen valores compartidos como deberes que guían el sentido de la acción social.

La situación de conflicto supone antagonismo entre los sujetos envueltos. Actuar en comunidad como posibilidad de solidaridad social en la Justicia en Equidad supone facilitar vías de diálogo orientado hacia la consecución de acuerdos consensuados. Para algunos informantes las conciliaciones contribuyen a desdibujar la rivalidad y traducirla en amabilidad y hasta amistad. 
Mire que se van conociendo cuáles son los problemas, eso ayuda a que la otra persona [...] por ejemplo: si yo debo, entonces el señor me dice "es que con esa plata iba a pagar el hospital de mi abuelo", entonces iay juepucha! qué pena con el señor, mire que hay que buscarle una alternativa. La otra persona que está allá, que le tenemos que cumplir, le dice "no, es que quedé mal, fracasé, no pude con el negocio, se me perdió esto", entonces dice, "no, es que el tipo tampoco tenía la intención de tumbarme todo eso". Ahí es donde la gente empieza a conocerse y el diálogo suscita entre las personas una familiaridad [...]. (O3, comunicación personal, 27 de mayo de 2017)

Los operadores consideran imprescindible el diálogo y resaltan que la exigencia principal de éste es el respeto entendido como valor, que así aduce deberes que guían los comportamientos (acción racional con relación a valores, Weber, 1973 [1913]). Estos deberes se resumen en la escucha de las versiones, propuestas y hasta vinculaciones emocionales de cada usuario, evitando frases insultantes o afrentas, sin entender a priori, al menos no hacerlo evidente, uno de los relatos del conflicto como más verosímil y justo que el otro.

El valor más importante es el respeto, siempre, el valor de que la persona no se parcialice [...] siempre buscar que haya un buen acuerdo". (O2, comunicación personal, 31 de mayo de 2017)

Cada uno expresa lo que piensa, lo que siente, lo que quiere y de ahí es donde se extracta de pronto una posible solución. Si no se llega a la instancia del dialogo, entonces ahí es donde van y le meten candela, le echan ácido, le pegan un par de puñaladas, un par de tiros o simplemente lo esperan en la esquina o le mandan otros dos porque no se acude a este tipo de instancias [...]. (U1, comunicación personal, 22 de junio de 2017)

Así, tanto operadores como usuarios entienden que el diálogo mediado es propicio para discutir arreglos amistosos, noviolentos ${ }^{8}$ y empáticos, de los que surgen comprensiones ampliadas del conflicto (que no se limitan

8 El concepto de la noviolencia fue acuñado así por Aldo Capitini (1931) para separarlo de la negación pasiva a la violencia y asociarlo, mejor, a una acción de rechazo contundente, como respuesta activa y alternativa para resolver conflictos. 
a una sola versión). Son éstas, entonces, las características distintivas de actuar en comunidad con respecto a los conflictos sociales cotidianos.

Sin embargo, no todos los participantes del conflicto entienden el diálogo de la Justicia en Equidad con esas características, sino que presuponen otras, propias de formas de administrar justicia en la que prepondera la toma de una decisión unilateral y la articulación verbal que la hace impositiva. Entonces, en el caso de la Justicia en Equidad, el actuar en sociedad se instaura cuando se considera un consenso directo insatisfactorio, prefiriendo que la solución se ajuste a marcos de referencia normativa legal, como orden estatuido y requerimiento unilateral subsiguiente (Weber, 1973 [1913]), por lo que la acción racional se orienta a fines y no a valores.

Así, actuar en comunidad no es la única acción social posible en la Justicia en Equidad, en el diálogo se usan expresiones propias del derecho positivo que imprimen otros sentidos -distorsionados- a la instancia: a) los calificativos dirigidos hacia los operadores como "doctor", "doctora", "ley" o "jefe"; b) preludios formales (solemnes, protocolarios) de los operadores en momentos determinantes de las conciliaciones; c) términos oficiales para referirse a sitios "despacho", situaciones "llamar a relación" o tipologías de conflictos "restitución de inmuebles" y d) expectativas encubiertas de los usuarios que parten de suposiciones frente al alcance de las facultades (poderes coactivos) de los operadores.

Una vez ha terminado la operación de diligencia de los dos formatos $\mathrm{O} 2$ dice "Aquí nos vamos a respetar como seres humanos y a ser muy claros". Fue una frase previa para dar la palabra a los usuarios que expusieron sus versiones y perspectivas por turnos que moderó $\mathrm{O} 2$. El solicitante fue el primero, O2 se anticipó a éste con la frase "dígale a este despacho por qué demandó a la señora" [...]. (Audiencias con O2, observación directa, 13 de junio de 2017)

La gestión de los conflictos no sólo se sujeta a valores (y con ellos a deberes aducidos y compartidos, subjetivamente provistos de sentido hacia arreglos amistosos), aunque son los primeros buscados, también a intereses (y con ellos a expectativas de acción de acuerdo a marcos 
normativos legales impersonales como requerimientos unilaterales de órdenes estatuidos). La convergencia de ambos, la exclusión de uno o la preminencia de uno sobre otro, dependen del cálculo intersubjetivo sobre la orientación de la acción más efectiva (por sus posibilidades fácticas aproximadas) para resolver los conflictos.

Para efectos analíticos, se han distinguido casi tajantemente las situaciones en que se da el actuar en comunidad y el actuar en sociedad. ${ }^{9}$ No obstante, como es común en toda la obra weberiana, aquellos conceptos corresponden a tipos ideales, por lo que en el curso práctico de las audiencias y de sus discursos, estas formas de acción social aparecen, sino superpuestas, entremezcladas (tal como lo hacen también las tipologías de acción racional). Así, en una misma audiencia ya citada en la categoría del sentido de lo justo comunitario (Audiencias con O1, observación directa, 22 de junio de 2017) se presentaron alusiones a la conciliadora en equidad como "doctora" y la frase ceremonial y vinculante "lo que firman ahora se considera cosa juzgada y es de estricto cumplimiento", apuntando a un actuar orientado a un orden estatuido (legal) del cual se desprenden las expectativas de las usuarias en arreglo a sus fines, calculando las consecuencias de infligir tal orden, junto al relato de una historia ficticia por parte de la conciliadora con llamamiento de valores como ejemplaridad y respeto, que elevó el "deber madres" de acuerdo a su rol de tutoras, para que sus hijos no se involucraran en el escalamiento del conflicto, calculando los chances de que los sujetos ajustaran la conducta a ese valor, subjetivamente mentado, como conducta deseable, sabiéndose que:

[...] actuar en comunidad, en modo alguno, se agota en la orientación en vista a "expectativas" del "actuar" de terceros en especial. En el caso límite puede prescindir por entero de estas, y el actuar referido por su sentido a terceros puede estar orientado de manera exclusiva al "valor", subjetivamente creído, de su contenido de sentido en cuanto tal ("deber" u otro), en cuyo caso no se orienta en vista de expectativas sino de valores. (Weber, 1973 [1913], p. 190) 
La inclusión intercultural (Ardila, 2006; Chiroleu, 2009; Subirats, 2010) se vuelve cuestión de estudio en la Justicia en Equidad, pues ella se desenvuelve en contextos sociales de referencia donde coexisten relaciones culturales heterogéneas, con sentidos de pertenencia, identidad, formas de solucionar conflictos y estructuras normativas diversas y válidas.

Para los operadores, esta diversidad, que bien puede motivar conflictos, ha de tramitarse orientando el diálogo a través de valores y creencias que los sujetos consideren comunes, incluso reelaborándolos.

Se me presentó uno que vivía en un apartamento y que porque es homosexual. Lo primero que les dije: la personalidad de él, sea de aquí, sea de allá, aquí estamos tratando es la convivencia en el apartamento, el respeto que él debe de tener con las demás personas, pero dentro del apartamento él puede hacer lo que se le dé la gana siempre y cuando no haga escándalos [...], y usted tiene que respetarle la personalidad a él [..... (O1, comunicación personal, 26 de mayo de 2017)

El valor de la libertad se reelaboró reflexivamente, asumido de acuerdo con la noción de límite ${ }^{10}$ por parte de la operadora, pues se entendió como el derecho de una persona homosexual de expresar libremente su personalidad, sin ser sujeto de señalamientos, estigmatizaciones y exclusión en su lugar de residencia, pero sin perturbar la vida doméstica de los hogares aledaños con excesos de ruido, expresiones soeces o uso inapropiado de las áreas comunes.

Los usuarios consideran que sus perspectivas y propuestas de solución, aunque controvertidas y diferentes, son escuchadas en las audiencias por igual, pues tienen oportunidad de expresarlas y defenderlas. Reconocen responsabilidad sobre las mismas y que el resultado del acuerdo no es la consignación exacta de ellas, sino de soluciones conciliadas. Además, consideran que el diálogo se orienta sin discriminación alguna, lo cual consideran como condiciones de igualdad.

10 Acerca de la noción de derecho limite y el debate jurisprudencial contemporáneo véase a los autores Catoira (1998) y de Luque (1993) y sus respectivos artículos. 
Saberlas también manejar. Uno tiene que así llegue el rico, el pobre, el sucio, el limpio o el desarreglado, atenderlos a todos por igual, me parece muy importante, uno atender a todo mundo por igual [...]. (O4, comunicación personal, 29 de julio de 2017)

Los operadores identifican que unos usuarios están en desventaja frente a otros. La forma de equilibrar la situación, al menos en las audiencias, se resume en garantizar la escucha de cada uno de los relatos y pretensiones sobre el conflicto y la imparcialidad que denota ser una instancia de resolución de conflictos. Entonces, el acceso a administración de justicia es el derecho que los sujetos en conflicto gozan en condiciones de igualdad.

\section{Retórica}

Es la cuarta categoría y aunque tiene asiento teórico, se describe como emergente dados los elementos novedosos que los hallazgos sugieren de la misma. Definida en el sentido clásico y aristotélico "como la facultad de considerar en cada caso lo que cabe para persuadir" (Cárdenas Mejía, 2006, p. 87), en la Justicia en Equidad, a través del diálogo informal, autocompositivo y argumentativo, los sujetos se hacen a elementos coactivos, emotivos y tradicionales, en la comunicación verbal y no verbal, como actos perlocucionarios (Searle, 2001, en Cárdenas Mejía, 2006), entendidos aquí como efectos persuasivos sobre los interlocutores.

En cuanto a los elementos coactivos, se presentan a modo de advertencias y exhortaciones sobre las consecuencias no deseadas para los interlocutores, de no ceder ante ciertas pretensiones. Contiene entonces menciones genéricas o vagas de sanciones contempladas en leyes, la ilustración sobre efectos perjudiciales de las medidas que pueden tomar los jueces de paz en la emisión de fallos en equidad, las medidas de la justicia ordinaria que aparecen frente a la conciliación menos deseables e incluso que, ante la negativa de conciliar, hay más probabilidades de que el conflicto se torne agresivo.

Si el señor no quiere desocupar, entonces ya se le explica: "si usted no desocupa, vea que hay que hacerle el desalojo, mire que si le hacen 
el desalojo le va a costar esto y esto". Entonces la gente accede a hacer las cosas [...]. (O1, comunicación personal, 26 de mayo de 2017)

"Yo lo había llamado a él-le decía el solicitante a O2-y las últimas veces terminaba insultándome". El solicitado replica "no, yo reconozco, pero usted también reconozca que me trato mal". El solicitante, mientras miraba fijo a su contraparte, afirmó durante la audiencia: "por eso yo prefiero venir acá antes que meterme en problemas", el solicitado alzó los hombros y asintió con la cabeza. (Audiencias con O2, observación directa, 10 de mayo 2017)

En cierta medida, corresponden estos elementos coactivos a los componentes de burocracia y violencia infiltrados en el campo semántico de la retórica, retomando la tesis de Santos (2001); no obstante, los sujetos en conflicto los expresan en tanto los consideran mecanismos disuasivos eficaces cuando otros (los tradicionales y emotivos) no lo han sido, es decir, al exponer una situación hipotética límite e indeseable para todos los interlocutores, al menos en principio.

En lo que atañe a los elementos emotivos, la retórica comprende que a la palabra, como forma de expresión, no precede sólo raciocinios estoicos o impasibles, sino "pasiones" o "afecciones del alma", como los llamaría Aristóteles (Cárdenas Mejía, 2006), para lograr su efecto persuasivo en una trama argumentativa. Especialmente entre los usuarios se observaron en audiencias gestos, tonalidades de voz y frases que manifestaban sentimientos, recelos, referencias a situaciones personales desvinculadas del trámite jurídico estricto (formal) pero que se creen parte de la configuración cotidiana del conflicto.

El usuario solicitado se quejó por las actitudes de la madre del solicitante, cuando iba a la casa a cobrar el arrendamiento, al mirar a su compañera sentimental y a sus hijas. El solicitante aclaró que su madre era seria y que no pretendía generar malestar al mirar, como tampoco él lo hacía. Afirma que saluda a las hijas del solicitado de manera convencional, sin pretender hacerles reclamos por las deudas con su padre. (Audiencias con O2, observación directa, 10 de mayo 2017)

Los elementos tradicionales se manifiestan en la Justicia en Equidad a modo de parábolas y adagios populares, cuentos e historias ficticias y 
Dios como 'verdad formular' (Giddens, 1997) empleados para persuadir. La equidad, según los operadores, también se orienta por valoraciones religiosas, particularmente de la tradición judeo-cristiana. Así, los operadores establecen símiles con la Biblia, afirman que Dios guía su proceder en la administración de justicia y hasta aseguran que entender la equidad exige la posesión de cierta sabiduría arcana, relacionada con tradiciones remotas.

Por eso mismo es que tenemos que tener la capacidad de que usted ve que allí hay una religión inmediatamente convoque a Dios y ahí frena todo, todo el mundo muestra el respeto [...] y buscamos el diálogo, el apoyo en que verdaderamente hay que respetarnos [...]. (O2, comunicación personal, 31 de mayo de 2017)

Los refranes, dichos y adagios se convierten en elementos disuasivos que utilizan los operadores en equidad, más cercanos al lenguaje cotidiano de los sujetos en conflicto que la asunción de la fuerza impositiva de artículos, leyes u otras normas legales.

La usuaria acudía a esta instancia después de ir a otras sin éxito. O2 utilizó el refrán "si se cansa la vaca de darle la leche al becerro, hasta lo patea y lo cornea, cómo no se va cansar uno, la misma naturaleza nos enseña". Es usual que utilice frases como éstas para entender las motivaciones de los conflictos en diálogo con los usuarios a través de metáforas, relacionadas con la vida rural. (Audiencias con O2, observación directa, 13 de junio de 2017)

La alusión a la tradición es efectiva si antes de imponer implica interpretar. El contenido normativo está fuertemente ligado a concepciones morales cuya fuente o marco se relaciona con lo sagrado y lo religioso (verdad formular). El sentido de lo justo comunitario está en que los sujetos pueden interpretar la normatividad que reviste su acción cotidiana sin denotar experticia o competencia. Interpretar significa entender el conflicto (lo bueno y lo malo, lo justo y lo injusto) en interacción dialógica.

Toca involucrarse con ellos, saber qué piensa una persona que viene de la gran capital como lo que pensamos acá icómo se vincula 
uno con ellos? en una reunión, en una tomada de un tinto...en tratar de mirar cómo se desarrollan ellos y bregar a compactar todo eso para tratar de buscar una solución, fuera de las normas [...] es que el límite de la Justicia en Equidad es la Constitución, pero lo primordial de esta justicia es saber qué piensa la gente [...]. (O3, comunicación personal, 27 de mayo de 2017)

La Justicia en Equidad, por medio de la retórica, se erige como espacio para reelaborar la tradición, pues no se hereda y acepta sin más, sino que sugiere la generación de nuevas formas de solidaridad social, que a su vez requieren nuevos nombramientos en las teorías sociales.

\section{Conclusiones}

De los resultados presentados se concluye que, por un lado, el sentido de lo justo comunitario es, sobre todo, un sentido consensuado que parte de la mezcla de estructuras normativas extralegales y legales para discutir conflictos. Tales estructuras son identificables en cuatro atributos:

a. El significado, ampliamente aceptado, de justicia y equidad como cuestión distributiva y limitada, dado un orden de cosas que existe en relación dialéctica con lo que lo descompensa, esto es, la injusticia.

b. En la normatividad evocada, que suele relacionarse con elementos de cohesión social como tradiciones, valores, costumbres, sentido común, adagios populares y deberes comprensibles para las personas de a pie "no-expertos", como formas de regulación social frente a comportamientos que buscan justicia privada, evitando la anomia y la criminalidad.

c. En un diálogo mediado por una persona que goza de reconocimiento cívico y legal, y caracterizado por un trato "respetuoso" y "cordial", de acuerdo con las normas sociales evocadas, en el que se permiten manifestaciones emotivas y coloquiales para expresar y entender el conflicto, con lo que se busca generar empatía.

d. En su legitimidad, que deviene de la legalidad que fundamenta sus productos formales (actas de conciliación) y el deber social que revisten sus acuerdos, dada una valoración intersubjetiva. 
Teniendo en cuenta los atributos descritos, el sentido de lo justo comunitario se configura siempre de manera dialógica y diversa, pues la estructura extralegal normativa es cambiante, continuamente reelaborada en los discursos de los sujetos en conflicto. Así, es contradictorio y no necesariamente homogéneo, pero procura, a partir del reconocimiento del disenso -indeseable, aunque real- constituir formas de consenso deseables y posibles.

En el contexto de Armenia (Quindío), la legitimidad del sentido de lo justo comunitario, aunque reconocida en situaciones de conflicto interpersonales, ve su posibilidad reducida por su disminuida articulación con el campo jurídico oficial y el poco reconocimiento de la sociedad, resultado de una débil institucionalidad. La Justicia en Equidad se presenta entonces como una instancia aislada y fragmentada.

Por otro lado, la noción de conflicto se relaciona con el disenso y el desacuerdo en su motivación y en sus formas tipológicas de realización. Entre los operadores prevaleció la clasificación legal al referirse a los conflictos en que intervenían e hicieron lecturas en que los vinculaban con problemas sociales, lo que permitía el cambio de perspectivas hacia exámenes más amplios del conflicto entre los usuarios, considerando la visión y posición de sus contrapartes, afectando incluso el cumplimiento cabal de los acuerdos, atendiendo a una suerte de trato más deferente.

En lo que respecta al vínculo entre Justicia en Equidad y la cohesión social, éste resulta a través de la palabra como medio de interacción, caracterizada dentro de lo observado, por partir de un diálogo mediado, intercultural y en condiciones de igualdad, esto es, sin discriminación por orígenes étnicos, orientación sexual, creencias religiosas u otras expresiones de diversidad cultural. Este carácter de interculturalidad apareció en su potencialidad más favorable, pero investigaciones futuras podrán contrastar su alcance, proponiendo incluso balances críticos, teniendo en cuenta que entre el sentido común y los juicios morales no siempre se encuentran perspectivas incluyentes.

Este diálogo está dado en términos informales, del cual los interlocutores comprenden, racionalmente, el conflicto de manera ampliada (sin limitarse a una sola versión). Sobresale en aquél valores y deberes aducidos afines con el respeto, que conducen las conductas de los sujetos 
envueltos en conflictos hacia relacionamientos noviolentos, empáticos y cercanos a lo amistoso, interpretadas aquí como formas de actuar en comunidad.

Sobre todo, es un diálogo de juegos de persuasión en el que la retórica permite usar elementos emotivos, tradicionales y coactivos en una trama argumentativa en la que artefactos verbales y no verbales (gestos, señas $\mathrm{y}$ tonalidades de voz) son los instrumentos comunicativos permitidos.

Aunque aumentan las investigaciones y con ellas el interés intelectual, en los estudios del derecho en Colombia, la pluralidad jurídica y las justicias comunitarias apenas se abren paso, tratándose todavía de temas poco abordados. En el trabajo social la situación es mucho más precaria, por ello, a la luz de los resultados, cabe acotar algunas consideraciones.

El trabajo social contemporáneo, entendiendo que la orientación del quehacer profesional vira hacia el cambio social y a la intervención de problemas en el curso de las relaciones humanas (FITS, 2001), buscando alternativas de paz y libertad, exige a los trabajadores sociales acercarse, como preocupación intelectual y axiológica, a las perspectivas de la realidad social que tienen los sujetos con quienes convergen en la actuación profesional, de manera crítica y reflexiva, como apuntan las discusiones sobre el proyecto ético-político profesional. ${ }^{11}$

Así pues, ante grandes problemas sociales como las vulneraciones de derechos humanos causados por las violencias, puede acercarse a las formas en que estas se originan en la cotidianidad, particularmente en contextos sociales de referencia en los que las relaciones existentes se caracterizan por una alta conflictividad, partiendo de cómo para los sujetos envueltos en conflictos cotidianos se configuran las confrontaciones y las posibilidades de resolución, para luego preguntarse por las estrategias de intervención profesional, articuladas a formas noviolentas y comunitarias de gestión de los conflictos, como la Justicia en Equidad.

11 Discusiones en las que sobresalen los aportes de Travi, 2016; Montaño, 2014; Fóscolo, 2007; Aquín, 2005; Barroco, 2003 y Netto 1999. 


\section{Referencias}

AIETS \& FITS. (2004). Estándares globales para la educación y capacitación del trabajo social. Recuperado de http://cdn.ifsw.org/assets/ifsw_104521-1.pdf

Ardila, É., Zapata, M., Jaramillo, P., Santos, I., Gamba, I., E Ramírez, L. (2006). ¿A dónde va la justicia en equidad en Colombia? Bogotá: Corporación Región. Recuperado de http://datateca.unad.edu.co/contenidos/90130/lectura_Guia_N_1._A_DONDE_VA_LA_JUSTICIA_EN_EQUIDAD_EN_COLOMBIA_1_.pdf

Ardila, E. (2004). Claves para el estudio de las políticas en justicia comunitaria. El Otro Derecho, (30), 75-101. Recuperado de http://docplayer.es/3421478Claves-para-el-estudio-de-las-politicas-en-justicia-comunitaria-edgar-ardilaamaya.html

Ardila, E. E Castro-Herrera, F. (2017). La conciliación en equidad como institución comunitaria. En F. Castro-Herrera, E. Ardila E J. Jaramillo (Eds.), Huellas $y$ trazos de la justicia comunitaria en Colombia: una década de aportes y desafios de la Escuela (pp. 167 - 190). Bogotá, Colombia: Universidad Nacional de Colombia.

Atehortúa, C. E Hincapié, S. (2005). Nociones y Percepciones de Justicia. Jueces y Conciliadores en Equidad. Recuperado de https://www.academia. edu/25688348/Nociones_y_percepciones_de_justicia_jueces_y_conciliadores_en_equidad

Barba Solano, C. (2011). Revisión teórica del concepto de cohesión social: hacia una perspectiva normativa para América Latina. En C. Barba Solano E N. Cohen (coords.), Perspectivas críticas sobre la cohesión social: desigualdad y tentativas fallidas de integración social en América Latina (pp. 67-86). Buenos Aires, Argentina: CLACSO. Recuperado de http://bibliotecavirtual.clacso. org.ar/clacso/clacsocrop/20120328120445/4.revision_barba.pdf

Cárdenas Mejía, L. (2006). El lenguaje, la persuasión y las pasiones. Estudios de Filosofía, (33), 87-98. Recuperado de https://aprendeenlinea.udea.edu.co/ revistas/index.php/estudios_de_filosofia/article/view/12824/11555

Chinchilla, T. E. (2008, 8 de septiembre). Anomia. El Espectador. Recuperado de https://www.elespectador.com/opinion/anomia-columna-37004

Corporación Excelencia en la Justicia (CEJ). (2011). Distribución de Jueces de Paz en Colombia. Recuperado de http://www.cej.org.co/index.php/todos-justi/2590distribucion-de-jueces-de-paz-en-colombia 
De Sousa Santos, B. (2001). Los paisajes de la justicia en las sociedades contemporáneas. En B. de Sousa Santos \& M. García-Villegas (eds.), El Caleidoscopio de las Justicias en Colombia. Análisis socio-jurídico (Tomo I) (pp. 85-150). Bogotá, Colombia: Siglo del Hombre Editores, Universidad de los Andes.

Elecciones de jueces de paz. (2002, 29 de septiembre). El Tiempo. Recuperado de http://www.eltiempo.com/archivo/documento/MAM-1324304

Giddens, A. (1997). Vivir en una sociedad postradicional. En U. Beck, A. Giddens \& S. Lash, Modernización reflexiva (pp. 75-136). Madrid, España: Alianza Editorial.

Fernández, A., Vega, L. E Giraldo, N. (2013). Panorámica del Homicidio en el Quindío 2005-2012. Plataforma de información en conflicto y violencia. Armenia, Colombia: Observatorio Social-Universidad del Quindío.

Gergen, K. (2006). El yo saturado. Dilemas de identidad en el mundo contemporáneo. Barcelona: Paidós.

Hernández Sampieri, R., Fernández Collado, C. E Baptista Lucio, P. (2010). Metodología de la investigación. Ciudad de México: McGraw-Hill.

Illera, M., García, A. E Ramírez, M. (2012). Justicia de paz y conciliación en equidad: ¿Formas alternativas de resolución de conflictos comunitarios en Barranquilla (Colombia)? Revista de Derecho, (edición especial julio de 2012), 307-329. Recuperado de https://www.redalyc.org/articulo.oa?id=85123909012

Lorenzo Cadarso, P. L. (1995). Principales teorías sobre el conflicto social. Norba Revista de Historia, (15), 237-254. Recuperado de https://dialnet.unirioja.es/ descarga/articulo/241031.pdf

Pinzón, R. (2007). Análisis del proceso de elección de los jueces de paz. El caso de la Localidad $8^{a}$ de Kennedy en la Ciudad de Bogotá, D. C. (tesis de maestría). Pontificia Universidad Javeriana, Bogotá, Colombia. Recuperado de https:// repository.javeriana.edu.co/handle/10554/295

Ramírez, M., Illera, M. E Llinás, H. (2012). Los centros de conciliación: su percepción, conocimiento y uso por parte de los ciudadanos de Barranquilla. Revista Civilizar, (12), 35-48. Recuperado de http://www.scielo.org.co/scielo. php?pid=S1657-89532012000200004Escript=sci_abstractEtlng=es

Subirats, J. (2010). Ciudadanía e Inclusión Social. El Tercer Sector y las políticas públicas de acción social. Recuperado de http://fundacionesplai.org/tercer-sector/ debates-del-tercer-sector/ciudadania-inclusion-social/

Torregrosa, N. (2011). Conciliación en equidad: Representaciones sociales sobre el concepto de conciliación en equidad de los operadores de la justicia en equidad en Bogotá. Revista Diálogos de Saberes, (34), 49-62. Recuperado de https://dialnet.unirioja.es/descarga/articulo/3718268.pdf 
Torregrosa, J. \& Torregrosa, N. (2014). Representaciones sociales, conciliación en equidad y justicia comunitaria: un estudio de caso. Revista Internacional de Ciencias Sociales Interdisciplinares, 3(1), 15-24. Recuperado de https://journals. epistemopolis.org/index.php/csociales/article/view/1133/0

Uprimny, R. (1994). Justicia y resolución de conflictos: la alternativa comunitaria. Pensamiento Jurídico, (1), 71-103. Recuperado de http://www.revistas.unal. edu.co/index.php/peju/article/view/38890

Weber, M. (1973 [1913]). Ensayos sobre metodología sociológica. Buenos Aires: Amorrortu Editores. 